University of Nebraska - Lincoln

DigitalCommons@University of Nebraska - Lincoln

Anthropology Faculty Publications

Anthropology, Department of

1985

Sex Differences in the Recognition of Infant Facial Expressions of Emotion: The Primary Caretaker Hypothesis

Raymond B. Hames

University of Nebraska-Lincoln, rhames2@unl.edu

Wayne A. Babchuk

University of Nebraska-Lincoln, wbabchuk1@unl.edu

Follow this and additional works at: http:// digitalcommons.unl.edu/anthropologyfacpub

Part of the Behavior and Ethology Commons, Biological and Physical Anthropology Commons, Child Psychology Commons, and the Social and Cultural Anthropology Commons

Hames, Raymond B. and Babchuk, Wayne A., "Sex Differences in the Recognition of Infant Facial Expressions of Emotion: The Primary Caretaker Hypothesis" (1985). Anthropology Faculty Publications. 159.

http://digitalcommons.unl.edu/anthropologyfacpub/159

This Article is brought to you for free and open access by the Anthropology, Department of at DigitalCommons@University of Nebraska - Lincoln. It has been accepted for inclusion in Anthropology Faculty Publications by an authorized administrator of DigitalCommons@University of Nebraska Lincoln. 


\title{
Sex Differences in the Recognition of Infant Facial Expressions of Emotion: The Primary Caretaker Hypothesis
}

\author{
Wayne A. Babchuk, Raymond B. Hames, and Ross A. \\ Thompson
}

University of Nebraska, Lincoln, Nebraska

\begin{abstract}
Athough much research has been devoted to studying sex differences in functioning (e.g., Maccoby and Jacklin 1974), most efforts have been directed toward documenting or elucidating the proximate causes of sex differences. Few attempts have been made, however, to explain the ultimate causes of these differences or the elective pressures that have led to the development of paychological differences between males and females [for exceptions see Symons (1979) and Daly and Wilson (1983)]. Toward this end of blending psychology with erolutionary theory we develop what we call the "primary caretaker hypothesis," which predicts that the sex that through evolutionary time has dominated infant caretaking will differentially exhibit skills that are important in caretaking (e.g., the ability to rapidly recognize infant emotional expressions). Evidence is advanced to show that females dominate childcare in nonhuman primates and humans and that a high level of care of infants is crucial, given universally high infant mortality rates throughout our evolutionary history and the number of potential hazards impairing infant development. The prompt and accurate recognition of infant emotional cues-especially in the face-is an important component - caretaking practices, and thus selective pressures should result in greater proficiency in this sbility in the ex that caretakes most. An experimental procedure is described where informants were tested in their speed and accuracy of identifying infant facial expressions of emotion. A statistical analysis of the resuits revealed that females were significantly more accurate and rapid than males in their discrimination of facial expressions and that previous experience in childcare had no effect on
\end{abstract}

Received November 2. 1983; revised July 18. 1984.

Address reprint requests to: Raymond B. Hames. Department of Anthropology, University of Nebraska. Lincoln. NE 68588. this sex difference. Follow-up research concerning the "primary caretaker hypothesis" is proposed.

Ke. Words: Expressions of emotion; Sex differences: Evolution.

\section{INTRODUCTION}

It is generally assumed that communicationthe ability to encode and decode information passed between conspecifics-is an adaptive trait. Rarely, however, have researchers attempted to inquire whether sex differences in communicative ability exist and to identify the differential selective pressures that underlie them. In this article we address a specific communicative ability, the ability of adult humans to decode facial expressions of emotion in their infants. We begin with a consideration of the phylogenetic background of human facial expressions of emotion and the evoiutionary function of facial expressions. We then formulate an evolutionary hypothesis that predicts that the sex that caretakes most should be more accurate and rapid in identifying infant facial expressions of emotion than the sex that caretakes least. A study is described that evaluates this evolutionary hypothesis against an alternative hypothesis that predicts that the ability to identify facial expressions of emotion in infants is a function of the amount of infant caretaking 
W. A. Babchuk, R. B. Hames, and R. A. Thompson

experience. We conclude with a discussion of the implications of our results and an outline of follow-up research.

\section{Phylogenetic Background}

Among nonhuman primates, communication can be achieved by a variety of means, but the facial region is the most effective and flexible in the transmission of social signals (Chalmers 1980, p. 72). In Chevalier-Skolnikoff's (1973) extensive review of the literature, a study of the primate order reveals that the greatest degree of facial mobility occurs among species who live in large social groups, where facial displays are crucial to the regulation of social interaction (ChevalierSkolnikoff 1973, p. 60). Some of these expressions seem to convey a primate's underlying emotional state and may also provide clues to the intensity of the emotional display as well (Chevalier-Skolnikoff 1973, p. 28). In addition, some investigators have postulated that these expressions are biologically adaptive and genetically transmitted (Ekman 1971, 1973; Izard 1978).

The comparison of nonhuman primate and human facial expression, though often subject to anthropocentric oversimplification, shows that interspecific differences are most probably related to phylogenetic history (Van Hooff 1976, p. 181; Steklis and Raleigh 1979, p. 258). Human facial expressions, then, are similar to those of the nonhuman primates (especially the pongids), and these similarities are well documented in the existing literature (Chevalier-Skolnikoff 1973, p. 83; Eibl-Eibesfeldt 1975, pp. 478-483; Van Hooff 1976, pp. 173-180). Van Hooff concludes:

. . except for lip smacking, the major categories of non-human primate facial displays are represented, in their basic form, in the human repertoire of primary emotions (Van Hooff 1976, p. 180).

More specifically, human facial expressions that depict fear, anger, happiness, sadness, and interest seem to have equivalents in the nonhuman primate repertoire of facial displays. However, not all human facial expressions of emotion have nonhuman primate equivalents. Human facial expressions depicting disgust and surprise, for example, do not seem to be part of the nonhuman primate repertoire (Van Hooff 1976, p. 180). Nevertheless, these general similarities between human and nonhuman primate facial displays suggest the evolutionary origins of these emotional expressions in humans.

\section{Human Facial Expressions and Communciation}

Human facial expressions such as happiness, sadness, fear, anger, surprise, and disgust appear to be universally recognized by humans ${ }^{1}$ (Ekman 1975, p. 39; Ekman and Freisen 1971; Izard 1971). These researchers have provided evidence for cross-cultural recognition among peoples of at least 12 literate cultures, and among the Fore and Dani, preliterate societies of New Guinea. This research provides additional support for the adaptive origins of human facial expressions of emotion.

Of course, in contrast to nonhuman primates, humans also use language and in juveniles and adults linguistic competence is fully developed and serves as the primary mode of communication, even when nonverbal cues are used. In the prelinguistic infant. however, certain verbal signals, bodily movement, and facial expressions appear to be the most important communicative modes (Hinde 1974, pp. 180-189). Infants employ verbal signals such as crying to indicate pain, hunger, and discomfort (Lester and Zeskind 1979, 1981; Wolff 1969) and cooing to indicate pleasure and contentment (Lester and Zeskind 1979; Trevarthen 1977) from an early age. In addition, a number of researchers have documented that facial motions such as smiling, grimacing, and expressions of fear and surprise expressions begin to develop in range and complexity after the first 3 months of life (Ambrose 1961; Blurton Jones 1972; Brannigan and Humphries 1972; Emde et al. 1978; Konner 1972; Malatesta 1982; and Stern 1971). Brannigan and Humphries (1972, p. 39), in a study of preschool children, indicated that facial expressions were used more commonly than language while children played even though children had acquired a fair mastery of their language. Thus, aside from certain vocal signals (e.g., crying), it appears that in the early years facial expressions constitute one of the most important modes of communication for infants because of their early onset and frequency of use.

There are at least three explanations for the development of infant facial expressions of emotion. First, facial expressions may have been de-

\footnotetext{
' Interest may also be a universal facial expression.
} 
signed by natural selection to communicate important information to the caretaker about the emotional state of the infant, enabling the caretaker to respond in ways that enhance infant survival and/or reduce the cost of infant care. Second, facial expressions may be a kind of "practice behavior" that allows an infant to develop full communicative competence using facial expression in later life. In this case, infant expressions would be similar to the prelinguistic babbling stage that infants experience as they practice and experiment with the phonological system of the language they will use in later life. Third, facial expressions may be devoid of any accurate or important informational content because they are simply random contractions of the facial musculature.

There are a number of reasons why we believe that facial expressions have evolved in infants to enable caretakers to enhance infant survival and/or to reduce the cost of infant care. Recent research reviewed by Malatesta (1982) indicates that caretakers respond to infant facial expressions in ways that reduce infant anxiety, discomfort, and tension or in ways that elicit expressions of positive affect. Caretaker responses, therefore, are not random and they are clearly designed to enhance infant well-being. If, for example, a caretaker ignored, misidentified, or responded randomly or slowly to an infant's expression of disgust when it ingested something noxious, the infant might fail to survive. Because human infants are relatively helpless it seems highly likely that selective pressures would exist to lead to the very early development of communicative abilities in infants that enable caretakers to care for them more effectively. Facial expressions and a more limited repertoire of vocal expressions seem to accomplish this purpose.

\section{The Primary Caretaker Hypothesis}

Among mammals, infant caretaking or parental investment is never equally divided between the sexes (Trivers 1972). Caretaking responsibilities fall primarily to the female although males may contribute significantly during particular stages of infant development (Kurland and Gaulin, in press). In a review of the literature on the role of fathers among nonhuman primates, Redican (1976) points out that although male caretaking reaches high levels in some monogamous apes (e.8, gibbons and siamangs) and in some New World monkeys (titis and marmosets), female care of infants is almost always greater than male care. Among humans the same pattern emerges, although human males appear more parental than most of their nonhuman primate counterparts (Katz and Konner 1981; and see below).

Given these consistent differences in levels of cretaking it seems probable that the ability to perform particular kinds of care of infants would differ for males and females in ways that directly relate to sex differences in patterns of parenal investment in offspring. Below we propose a model and identify some of the selective pressures that would lead to the development of different abilities in caretaking between the sexes.

Compared to industrialized and developing nations infant mortality rates in tribal societies are extremely high. However, if infant mortality rates of modern European societies are examined from the turn of the century to 300 years ago (Table 1) it is quite evident that the current low rate of infant mortality is a relatively recent phenomenon in human evolutionary history. Given this fact it is obvious that any sort of trait that would reduce infant mortality would have a high selective value. ' This is especially true for. a species, such as Homo sapiens, characterized by low rates of reproduction and high levels of pareatal investment in offspring. Because of the difficulties of engaging in sophisticated methods of biomedical research in isolated tribal environments, the causes of infant mortality are not completely understood. However, the consensus of opinion is that high levels of infant mortality result from the actions of a variety of infectious diseases and internal parasites (Black 1975; Neel 1976; Kaplan et al. 1980). Dietary problems, predation, and environmental traumas (c.8., accidents) sometimes occur but they

\footnotetext{
2 bhaston and Kensinger (1971) calculate Crow's Index of Toul Selection among the Cashinahua, an isolated Amazonian tribal population. This allows one to measure the roles of mortality and fertility in natural selection. They conclude that Clearly, selection is much more effective among the Cashimas when operating through deaths before the attainmert of reproductive ages" (Johnston et al. 1971, pp. 359360 ). Furthermore, they indicate that differential mortality is importan for other tribal societies but much less so for modern. iedustrialized societies (Table 3. p. 361). These observations support our contention that selection would operase powerfilly on infants and caretakers to evolve adaptations to reduce imfant mortality since infant mortality rates are greater than setes of juveniles.
} 
Table 1. Infant Mortality Rates in Tribal and Indararialized Societies

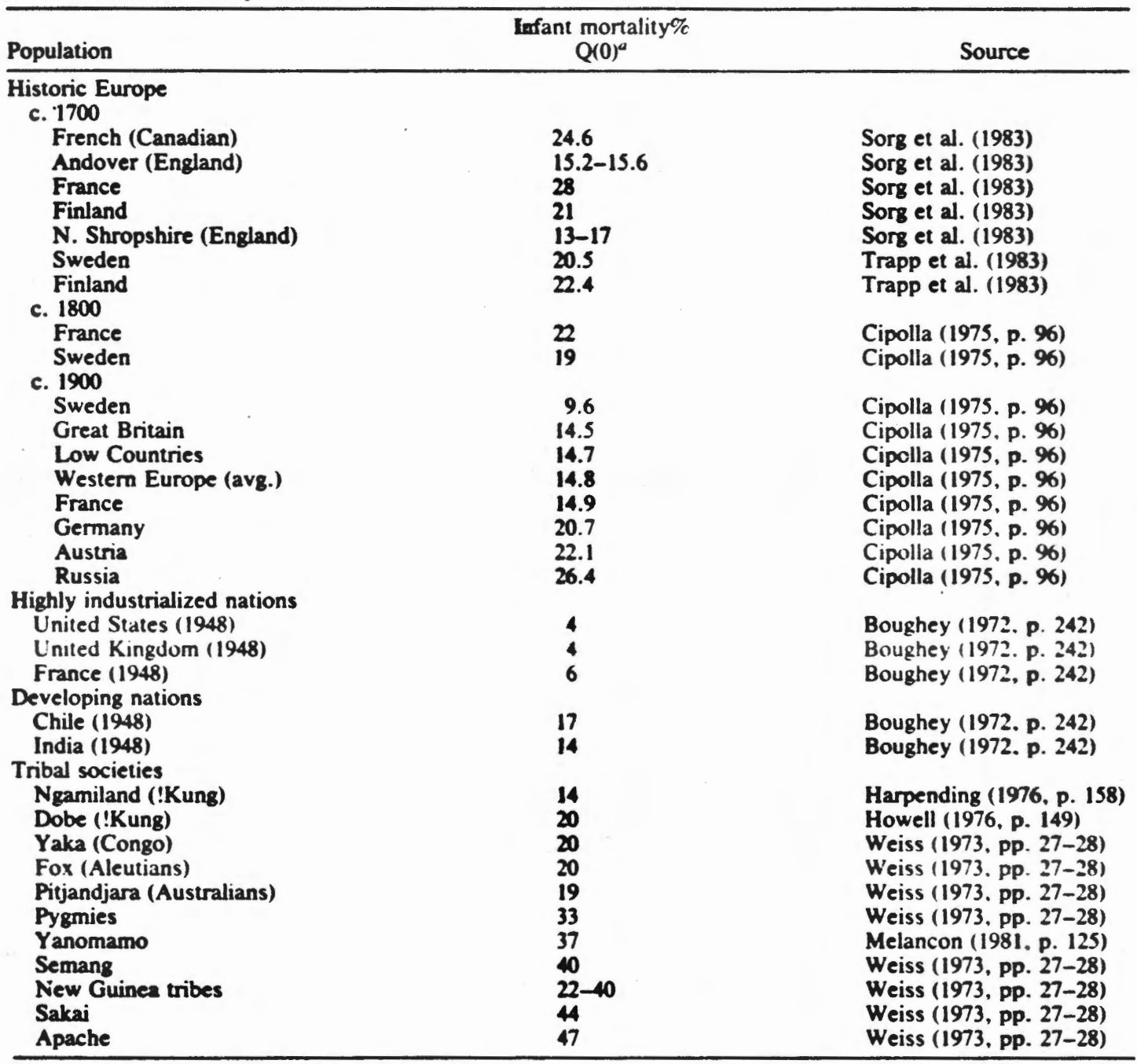

- Percent of all infants born who failed to survive their first year of life.

appear to be less significant sources of infant mortality (Konner 1972, p. 325). This is not to say that these factors do not influence caretaking behavior; rather, just the opposite-the maintenance of close proximity, careful monitoring. habitual carrying of infants, and feeding on demand that are so characteristic of parental behavior in tribal societies (Konner 1972, 1977; Draper 1977; Lee 1979) should be viewed as adaptations to enhance infant survivorship by reducing sources of infant mortality.

Given our evolutionary history of high levels of infant mortality and some of the adaptive functions of childcare behaviors described above that appear to reduce infant mortality, it is reasonable to suggest that infant facial expressions of emotion may play an important role in enhancing infant survivorship. An infant's expression of fear, distress, anger, and disgust immediately signals to a caretaker that something is wrong with the infant and that responses to diminish these expressions should be enacted by removing the source of upset. The exact cause of these expressions will vary with the form of childcare and the childrearing habitat. Facial expressions may be an infant's way of 
alerting a caretaker that something noxious or harmful has been ingested (i.e., disgust), that it is in pain or ill (i.e., distress), that it is being frustrated from accomplishing something (i.e., anger), or that it has perceived something dangerous (i.e., fear). Expressions of positive affect, on the other hand, may indicate to the caretaker that the infant is satiated, at ease, content, or absorbed in some learning process. Such signs of positive affect may tend to reduce levels of active care and allow a caretaker to more profitably allocate time to other important activities. Such signs may also induce the caretaker to behave in ways to maintain expressions of positive affect.

It is widely believed that females dominate childcare activities, especially the care of infants. Despite this understanding (or, perhaps, because of it) this generalization has only been established recently in a quantitative manner in industrialized societies (Table 3 ) and qualitatively in tribal societies (Table 2; and, e.g., Whiting and Whiting 1975; Katz and Konner 1981). Data in Tables 2 and 3 measure how much time mothers and fathers allocate to childcare activities. In many cases the data presented in these tables are not directly comparable because of differences in how childcare was defined and because no attempt was made to control factors such as how the number of children in a family affects time allocated to childcare. Neverthe- less, the tables do support the generalization that females allocate significantly more time to childcare than do males. This is especially true in tribal societies (see Table 2 ).

There is reason to believe that the data in Table $\mathbf{2}$ and, perhaps, in Table 3 underestimate the differences between males and females in their involvement with children. Table 4 displays a dimension of childcare not commonly measured or discussed (for exceptions see Blurton Jones 1972; Denham 1974; Konner 1977), which we simply call "child carrying." For example, among the Ye'kwana and Yanomamo Indians of Amazonas. Venezuela, infants and children up to 3 years of age are carried by their mother in a sling that positions the child astride her hip. but Ye'kwana and Yanomamo males never use the device to carry infants. This device and others (e.g., see Chisholm and Richards (1978) on cradle boards) are apparently very common among tribal peoples and especially among highly mobile hunter-gatherers (see Lee 19:9. Konner 1972, 1977; Tanner 1981). They allow the mother to care for her infant passively while engaged in all manner of economic and social activities. An infant carried in a sling has easy access to the mother's breast, is in ventral to ventral-lateral contact with the mother, and can easily view mother's face. Furthermore, in an analysis of !Kung hunter-gatherers, Blurton Jones and Sibly (1978) argue that child carrying

Table 2. Time Allocation (min/day) in Infant Care and Childeare

\begin{tabular}{lccccl}
\hline Group & Mother & Father & Other & Total & \multicolumn{1}{c}{ Reference } \\
\hline Tribal & & & & & \\
Machiguenga & $68(69 \%)$ & $8(8 \%)$ & $22(22 \%)$ & 98 & Johnson (1975) \\
Mekranoti & $67(85 \%)$ & $12(15 \%)$ & nd & 79 & Werner (pers. comm.) \\
Yanomami & $57(88 \%)$ & $8(12 \%)$ & nd & 65 & Lhermillier and Lhermillier \\
Ye'kwana & $53(74 \%)$ & $6(8 \%)$ & $13(18 \%)$ & 72 & Hames (orig. data) \\
Peasant & & & & & \\
Philippines & $102(78 \%)$ & $8(6 \%)$ & $21(16 \%)^{b}$ & 131 & Popkin (1980) \\
Nepal & $80(58 \%)$ & $15(11 \%)$ & $42(31 \%)$ & 137 & Nag, White, and Peet (1978) \\
Quechua & $50(86 \%)$ & $12(15 \%)$ & nd & 62 & Weil (1980) \\
Java & $48(39 \%)$ & $18(15 \%)$ & $58(48 \%)$ & 124 & Nag, White, and Peet (1978) \\
Mexico & $29(85 \%)$ & $5(15 \%)$ & nd & 34 & Erasmus (1955) \\
\hline
\end{tabular}

- It should be noted that the data in Table 2 do not indicate the total amount of time infants received care from various types of individuals. Rather, they indicate the average amount of time mothers. farhers, and others (usually siblings and kin of infant) spend in childcare activities. In each of these societies the amount af care a child or infant receives would be the sum of care allocated to them by all caretakers. Since most children in the societies in Table 2 have but one father and one mother (the Yanomami, Yanomamo, Ye'kwana, and Mekranoti permit polygyny but the vast majority of families are monogamous) this reliably indicates total care received from these individuals. However, for each child the category "other" usually measures the mean amount of time allocated by two to seven other people. Finsty. childcare is not consistently defined between studies therefore absolute time allocated by mothers and fathers in differeme societies may not be comparable.

- Indicates total of time allocated by siblings to child care and not allocation of siblings (see Popkin 1980, p. 9, Table 4). 
Table 3. Time Devoted to Childcare in Modera Industrialized Countries (min/day)

\begin{tabular}{|c|c|c|c|c|c|c|}
\hline & \multicolumn{2}{|c|}{$\begin{array}{c}\text { Employed } \\
\text { Married Men }\end{array}$} & \multicolumn{2}{|c|}{$\begin{array}{c}\text { Employed } \\
\text { Married Women }\end{array}$} & \multicolumn{2}{|c|}{ Housewives } \\
\hline & Workday & Day off & Workday & Day off & Weekday & Weekend \\
\hline $\begin{array}{l}\text { France } \\
\text { Belgium } \\
\text { USA } \\
\text { FRG } \\
\text { GDR } \\
\text { Bulgaria } \\
\text { Czechoslovakia } \\
\text { Poland } \\
\text { Hungary } \\
\text { Yugoslavia } \\
\text { USSR } \\
\text { Peru }\end{array}$ & $\begin{array}{l}13 \\
11 \\
12 \\
11 \\
19 \\
17 \\
25 \\
29 \\
29 \\
14 \\
23 \\
41 \\
6\end{array}$ & $\begin{array}{l}25 \\
19 \\
27 \\
26 \\
48 \\
15 \\
32 \\
46 \\
44 \\
16 \\
39 \\
53 \\
11\end{array}$ & $\begin{array}{l}64 \\
37 \\
50 \\
70 \\
44 \\
28 \\
37 \\
46 \\
43 \\
38 \\
36 \\
44 \\
34\end{array}$ & $\begin{array}{r}60 \\
48 \\
38 \\
79 \\
96 \\
34 \\
73 \\
82 \\
83 \\
68 \\
72 \\
102 \\
83\end{array}$ & $\begin{array}{r}136 \\
75 \\
100 \\
96 \\
122 \\
84 \\
119 \\
94 \\
76 \\
41 \\
62 \\
79 \\
69\end{array}$ & $\begin{array}{r}108 \\
29 \\
78 \\
57 \\
116 \\
\text { NA } \\
55 \\
29 \\
39 \\
33 \\
73 \\
118 \\
34\end{array}$ \\
\hline
\end{tabular}

- Minutes per day on all child activities (i.e. care, supervision of school work, reading books, conversations, indoor and outdoor ames, walks, instruction, medical care, etc.). Data from Szalai et a. (1972).

Table 4. Time Allocated to "Child Carrying" (min) day)

\begin{tabular}{|c|c|c|c|c|}
\hline Group & Mothers & Fathers & $\begin{array}{l}\text { Other } \\
\text { Female }\end{array}$ & $\begin{array}{l}\text { Other } \\
\text { Male }\end{array}$ \\
\hline $\begin{array}{l}\text { Ye'kwana } \\
\text { Yano- } \\
\text { mamo }\end{array}$ & $\begin{array}{l}109 \\
(n=7) \\
124 \\
(n=8)\end{array}$ & $\begin{array}{l}4.7 \\
(n=7) \\
4.8 \\
(n=5)\end{array}$ & $\begin{array}{l}16 \\
(n=12) \\
25.2 \\
(n=11)\end{array}$ & $\begin{array}{l}3.3 \\
(n=6) \\
3.0 \\
(n=1)\end{array}$ \\
\hline
\end{tabular}

- Data on Ye'kwana and Yanomamo child carrying behavior (collected by $\mathbf{R}$. Hames) was gained through scan sampling (Altmann 1974) during a 216-day observation period. Among the Yanomamo 15 infants between the ages of 0.4 and 3.0 years (are at end of study) were observed to be carried for an average of $118 \mathrm{~min} / \mathrm{day}$ and among the Ye'kwana 10 infants between the ages of 0.3 and 2.0 (age at end of study) for an average of $124.5 \mathrm{~min} / \mathrm{day}$. For both groups the amount of time a child is carried (as expected) declines with age: Yanomamo range from 7 to $323 \mathrm{~min} / \mathrm{day}$ and $Y e^{\prime} \mathrm{kwana}$ range from 3 to $274 \mathrm{~min} / \mathrm{day}$.

is so energetically costly that postpartum amenorrhea may result from a woman's inability to build up fat stores for regular ovulation. It is quite evident from the data in Table 4 that time devoted to this type of passive care is greater than traditionally measured forms of active care (e.g., feeding, comforting, and cleaning), thus further accentuating male and female differences.

In presenting the data in Tables 2, 3, and 4, it has been our aim to show that mothers dominate childcare activities and, as a result, are much more frequently observers and responders to infant facial expressions of emotion. Naturally, active and passive forms of childcare do not exhaust all infant-adult patterns of interaction where facial expressions of emotion might be expressed. However, a perusal of the ethnographic literature indicates that fathers engage much less frequently in other forms of interaction with infants than do mothers (e.g., Mackey 1979; Whiting and Whiting 1975).

If the expression of emotion by infants and a caretaker's ability to recognize them accurately and quickly enhances infant survival and thus the caretaker's reproductive success, it seems reasonable to predict that the sex that caretakes most will be able to recognize facial expressions in infants more quickly and accurately than the sex that caretakes least, or that the sex that caretakes most will be equal to but not inferior to the sex that caretakes least. This is not to say that males are not or cannot be competent caretakers of infants; there is evidence that they are (Lamb 1981; Parke 1981; Thompson 1983). Nevertheless, we hypothesize that females will be quicker and more accurate in their identification of infant expression of emotion than males and that such differences will be stronger than differences due to amount of prior caretaking experience alone (although there may be an interaction between sex and caretaking experience, with sex differences emerging when adults assume infant caretaking roles; cf. Nash and Feldman 1981). Below we review the data on sex differences in recognition of facial expressions and then describe experimental data we collected to evaluate our hypothesis. 


\section{Sex and the Ability to Recognize Infant Facial Expressions}

A survey of recent investigations of adult recognition of infant facial expressions reveals that contemporary investigators agree concerning the communicative value of these expressions. Emde et al. (1978) employed a multidimensional scaling technique in their study of adult judgments of facial expressions of $2 \frac{1}{2}-, 3 \frac{1}{2}-$, and $4 \frac{1}{2}$ month-old infants. They concluded that meaningul communicative messages can be sent by an infant during these early months of life-messages that become more coherent shortly after the third month (Emde et al. 1978, p. 145). Hiatt, Campos, and Emde (1979) utilized a components approach to the study of adult judgments of happiness, surprise, and fear facial expressions of 10-12-month-old infants in a variety of stimulus situations. They found that these expressions could be recognized by adults even without the benefit of situational cues, and that judges reported high levels of confidence in their judgments of infant facial expressions (Hiatt, Campos, and Emde 1979, pp. 1031-1032).

The findings of Izard et al. (1980) are consistent with those of Emde and Hiatt and their colleagues. Izard et al. (1980, pp. 138-139) provided evidence that untrained adults can, to varying degrees, accurately recognize at least eight infant facial expressions of emotion-interest, joy, surprise, sadness, anger, disgust, contempt, and fear (Izard et al. 1980, pp. 138-139). Furthermore, the accuracy of adult judges increased markedly when they were provided with special training that highlighted the distinctive features of different facial expressions of emotion in infants.

Surprisingly none of this research determined whether sex is a significant determinant of an individual's ability to recognize facial expressions of emotion in infants. Since this issue is central to an evaluation of the primary caretaker hypothesis, we recruited a sample of men and women who varied in the extent of their prior caretaking experience. Each was shown an array of slides portraying various facial expressions of emotion in infants and was asked to identify each expression as rapidly as possible. Using this procedure, we could obtain measures of both accuracy in identification and speed of reaction time and study whether these dependent meas- ures varied significantly according to the sex of the participant and the amount of prior caretaking experience. We studied both the speed and accuracy of infant facial expression recognition because these response characteristics in a caretaker are most relevant to the adaptive functions these expressions are thought to serve, and thus are likely to be subject to selective pressures. This research is unique because (1) it permitted us to compare the effects of sex and the amount of prior caretaking experience on facial identification, and especially to explore the interaction between these factors, and (2) response speed as well as accuracy were used as dependent measures. so that they could be compared.

\section{METHODS}

\section{Subjects}

Forty university students participated in this study. Their prior caretaking experience with infants and young children was assessed by a brief interview before participating in the research. Prior experience was defined as currently having one or more children under the age of 5 . Those with no experience reported never having assumed caretaking responsibilities with young children. There were thus four groups of subjects with ten members each: (1) males with no prior experience as caretakers of infants (average age 25.4 years); (2) males with experience as caretakers (average age 25.7 years); (3) females with no prior experience as caretakers (average age 24.2 years); and (4) females with experience as caretakers of infants (average age 27.3 years).

\section{Materials}

A total of 21 black-and-white slides depicting infant facial expressions of emotion were acquired from Dr. Carroll Izard of the University of Delaware. The slides consist of single frames from videotaped observations of infants in various stimulus situations and were selected to obtain the clearest exemplars of discrete facial expressions of emotion, based on characteristic constellations of facial muscle contractions associated with each expression when observed in adults (see Izard 1971). The infants pictured ranged in age from 1.3 to 21.1 months, with a mean age of 7.7 months; 12 of the 21 slides were of boys. There were three slides depicting expressions of joy, three of interest, two of surprise, three of sadness, two of fear, one of disgust, three of anger, and three of physical dis- 
tress. The remaining slide depicted a mixture of fear and anger expressions, and was eliminated from this array because it was an emotional blend. For the purposes of this study, the slides depicting sadness and physical distress were combined into one group because of the similarity of infant facial expressions in the two conditions.

The slides were projected on a screen by a Kodak 41010 slide projector with a Lafayette lens equipped with a shutter attachment. In the darkened room, the size of the slide when projected onto the screen measured $20 \times 13$ inches. Each subject viewed the slides from a distance of $7 \frac{1}{2}$ feet. A Lafayette Model 54417 clock counter and a Farrall Model SPR-1 voice relay with microphone were also used in the research.

\section{Procedure}

Each subject was seated in the testing room and given a written instruction sheet outlining the purposes of the study and the procedure. Subjects were asked to respond to each slide with the best word of their own choice to describe the infant's emotional expression as rapidly as possible. Following any questions, each slide was then projected once in random order. The slide projector activated the clock counter when the slide was projected onto the screen. The subject's verbal response into the voice relay microphone stopped the clock. The reaction time and verbal response were then recorded by the experimenter, after which the next slide was presented. Following the last slide, subjects were thanked for participating, and dismissed.

The accuracy of each verbal response was determined using Izard's (1971) Lexicon of Emotion Labels. Seven percent of the responses could not be classified according to this lexicon. In these cases, accuracy was assessed using Roget's Thesaurus and consultation among the authors.

\section{RESULTS}

For the sample as a whole, the infant facial expressions most accurately recognized were those of joy (average $98.3 \%$ correct responses), surprise $(81.1 \%)$, interest $(79.9 \%)$, and sadness/ distress $(\mathbf{7 5 . 5 \% )}$. In contrast, expressions of anger were recognized much less accurately (54.4\%), and fear (17.8\%) and disgust (2.5\%) expressions were poorly identified. ${ }^{3}$ A similar pattern was evident for reaction time. Expressions of surprise were recognized most quickly (average of 3.15 seconds), followed by joy (3.20 seconds), and sadness/distress (4.16 seconds). Expressions of anger (4.36 seconds), fear ( 5.14 seconds), and interest ( 5.30 seconds) were recognized less quickly, with expressions of disgust ( 7.38 seconds) requiring the most time to identify.

A series of two-way analyses of variance (ANOVA), with sex and caretaking experience as the two between-subjects factors, were performed on the accuracy and reaction time data. Analyses were performed for (1) mean values across the entire sample of slides, and (2) for mean values across clusters of slides in which the same emotional expression was depicted. For the accuracy scores across the entire array, the analysis revealed a significant main effect for sex $(F(1,36)=18.51, p<0.001)$, with women identifying infant facial expressions more accurately (mean of $74 \%$ correct resonses) than men (mean of $61 \%$ correct). There was no significant main effect for amount of prior caretaking experience, and no interaction between sex and experience. When the scores were averaged across slides displaying the same emotional expressions, women were found to be more accurate than men at identifying each of the seven different emotions presented in the slides. These sex differences were significant for expressions of surprise $(F(1,36)=6.45, p<0.02)$ and anger $(F(1,36)=8.70, p<0.007)$ and were marginally significant for fear expressions $(F(1,36)=3.17$, $p<0.085)$. There were no significant main effects for prior experience for any of the emotion clusters, nor were there any significant interactions between experience and sex.

The two-way ANOVAs for the reaction time data yielded a similar pattern of results. For the entire array of slides, women were significantly faster (mean of 3.94 seconds) than men (mean of 4.90 seconds) $(F(1,36)=4.86, p<0.035)$. There was no significant main effect for experience, and no interaction between experience and sex. Analyzing the responses clustered by the different kinds of emotional expressions, women were found to be quicker at identifying infant facial expressions than men for each of

\footnotetext{
${ }^{3}$ This pattern of findings concerning the accuracy of identifying infant facial expression of emotion is very similar to the one reported by Izard et al. (1980).
}

the seven emotions sex difference was surprise $(F(1,36)$ ginally significan $(F(1,36)=3.99, p$ effects for amount ence. There was, $t$ action of sex anc depicting disgust ( reflecting the fact and experienced $\mathrm{ft}$ reaction time scor no other significa experience.

DISCUSSION AND

To summarize, the that women were identify infant facis were men. In contr taking experience guished adults whi dren from those $w$ them-had a nons racy or response s: nificant interaction in either of these words, sex differen ident with variatio Taken together, th for our hypotheses the recognition of emotion. This sex it was not signific. of prior experience effect was stronge caretaking experie Our findings ac examining sex diff to caretaking (see Wiesenfeld, Mala found that mother distinguishing the familiar cries an kinds of cries (e. Feldman and Nas! in responsiveness parents of young more smiling, talk baby than men. I dence on caretakit tently show signir: 
the seven emotions depicted in the slides. This sex difference was significant for expressions of surprise $(F(1,36)=6.08, p<0.02)$, and marginally significant for interest expressions $(F(1,36)=3.99, p<0.055)$. There were no main effects for amount of prior caretaking experience. There was, however, a significant interaction of sex and experience for the slide depicting disgust $(F(1,36)=6.14, p<0.02)$, reflecting the fact that inexperienced males and experienced females obtained the slowest reaction time scores for this slide. There were no other significant interactions of sex with experience.

\section{DISCUSSION AND CONCLUSION}

To summarize, the results of this study indicated that women were more accurate and quicker to identify infant facial expressions of emotion than were men. In contrast, the amount of prior caretaking experience-which in this study distinguished adults who were parents of young children from those who had had little contact with them-had a nonsignificant influence on accuracy or response speed. There were also no significant interactions between sex and experience in either of these response measures; in other words, sex differences did not become more evident with variations in caretaking experience. Taken together, these findings provide support for our hypotheses concerning sex differences in the recognition of infant facial expressions of emotion. This sex difference was robust, since it was not significantly affected by the amount of prior experience in a caretaking role, and its effect was stronger than the influence of prior caretaking experience alone.

Our findings accord well with other studies examining sex differences in behaviors relevant to caretaking (see Berman 1980). For example, Wiesenfeld, Malatesta. and DeLoach (1981) found that mothers were better than fathers in distinguishing their own in nts' cries from unfamiliar cries and in differentiating different kinds of cries (e.g., hunger, pain, and so on). Feldman and Nash (1978) found sex differences in responsiveness to an unfamiliar baby among parents of young infants, with women showing more smiling, talking, and offering toys to the baby than men. To be sure, the research evidence on caretaking behaviors does not consistently show significant sex differences (Berman
1980) and there is evidence that the emergence of such differences varies with one's stage of life (Nash and Feldman 1981). Nevertheless, the weight of the evidence is consistent with the view that selective pressures may have fostered certain competencies related to caretaking in the sex that typically assumes the primary caretaking role, and our findings concerning differences in the speed and accuracy of identifying infant facial expressions of emotion further corroborate this view.

In our culture there are, of course, significant socialization pressures that shape the emergence of differences in sex-typed behaviors like caretaking and nurturance (Maccoby and Jacklin 1974), and our formulations are consistent with the strong role of social learning processes. From early in life, boys and girls are provided different opportunities to assume caretaking roles (Brooks-Gunn and Matthews 1979), and there is evidence that this is true in various nonWestern cultures as well (Weisner and Gallimore 1977). Thus by early adulthood, women and men have already experienced years of sex-typed socialization experiences. The influence of the selective pressures we have outlined suggests that. in addition, there may also be differences in the ease with which caretaking-relevant skills are acquired by men and women (Rossi 1977). All of these factors can account for why, in this research, women were more proficient than men regardless of differences in the amount of prior caretaking experience. We should note, however, that the men in this study were also competent evaluators of infant facial expressions, even though they lagged behind women on both response dimensions. Like the findings of most of the research on sex differences, in other words, there was considerable overlap in the distribution of scores for men and women even though their group averages were significantly different.

In evaluating these findings, we have argued that sex differences in identifying infant emotional expressions are related to selective pressures pertinent to the caretaking role. Alternatively, however, it may be argued that this difference is an unselected byproduct of a more general female superiority in the recognition of affect in others. Support for this view comes from a review by Hall (1978), who noted that in a large number of studies women were found to be significantly better decoders of nonverbal 
cues (including emotional cues) than were men, and that this sex difference was consistent regardless of the age of the stimulus person or the age of the judge. Although we know of no alternative adaptive explanation for this generalized female advantage, it is arguable that it may have evolved through sexual selection. That is, since women invest more in their offspring they are likely to be more discriminating in the selection of a mate [see Trivers (1971) for the theoretical basis for this generalization and Symons (1979) for empirical examples among humans]. Since male parental investment limits the quantity and/or quality of female reproduction. it may be advantageous for women to be capable of accurately assessing a male's willingness to provide paternal investment prior to mating or marriage. This assessment could be based on expressions of affect [see for example. Trivers (1971) on the emotional underpinnings of reciprocal altruism]. However, as Tiger (1969) has pointed out, males, more frequently than females, interact in highly organized, cooperative groups where accurate assessment of individual loyalty, commitment, and the like is crucial for individual success. Therefore, it appears that selective forces would lead to accurate assessment of emotion among male group members. Hence, we believe our explanation superior because it focuses on an adaptive constraint that is uniquely female and absolutely vital to female reproductive success.

As the foregoing makes clear, however, this study must be viewed as an initial attempt to provide empirical support for the primary caretaker hypothesis, with follow-up investigations needed to offer more substantial evidence. We have at least two such studies in mind. First, the speed and accuracy in identifying infant facial expressions of emotion can be examined within a multifactorial format in which the age of the stimulus person and the age, sex, and experiential background of the judge can be systematically varied. ${ }^{4}$ This would enable us to understand better the generality across ages of the female advantage in identifying facial cues of emotion as well as its developmental emergence within the life-span. Second, sex differences in sensitivity to other caretaking-relevant nonverbal cues in infants, such as postural and gestural tion. cues as well as vocal indicators of emotion, merits further exploration. This is important because effective caretaking obviously requires sensitivity to a variety of infant nonverbal cues besides facial expressions that also convey information about the infant's condition. We view both of these proposed studies as important ways of further assessing the primary caretaker hypothesis.

\section{REFERENCES}

Ambrose, J. The development of the smiling response in early infancy. In Determinants of Infant Behav ior, I. B. Foss (Ed.). London: Methuen, 1961.

Altmann. J. The observational study of behavior: Sampling methods. Behaviour 48: 1-21 (1974).

Berman, P. Are women more responsive to the young than men? A review of developmental and situational variables. Psychological Bulletin 88: 668-695 (1980).

Black, F. Infectious disease in primitive societies. Science 187: 515-518 (1975).

Blurton Jones, $\mathbf{N}$. Comparative aspects of mother-infant contact. In Ethological Studies of Child Behavior, N. Blurton Jones (Ed.). Cambridge: Cambridge University Press, 1972, pp. 305-328.

- Sibley, R.O. Testing adaptiveness of culturally determined behavior: do Bushmen women maximise their reproductive success by spacing births widely and foraging seldom? In Human Behavior and Adaptation. N. Blurton Jones and V. Reynolds (Eds.). Symposium No. 18 of the Society for the Study of Human Biology, London: Taylor and Frances, 1978.

Boughey, A. Man and the Environment. New York: MacMillan, 1971.

Brannigan, C., Humphries, D. Human non-verbal behavior, a means of communication. In Ethological Studies of Child Behavior, N. Blurton Jones (Ed.). Cambridge: Cambridge University Press, 1972, pp. 37-64.

Brody, S., Axelrad, S. Mothers, Fathers, and Children. New York: International Universities Press, 1978.

Brooks-Gunn, J., Matthews, W.S. He and She: How Children Develop Their Sex-Role Identity. Englewood Cliffs, NJ: Prentice-Hall, 1979.

Brown, R. A First Language: The Early Stages. Cambridge, MA: Harvard University Press, 1973.

Chalmers, N. Social Behavior in Primates. London: Edward Amold, 1980.

Chevalier-Skolnikoff, S. Facial expressions of emotion in nonhuman primates. In Darwin and Facial Expression, P. Ekman (Ed.). New York: Academic, 1973. 
Chisholm, J., Richards, M. Swaddling, the cradleboard, and the development of children. Early Human Development 2: 255-275 (1978).

Cipolla, C. The Economic History of World Population, 6th ed. London: Penguin, 1975.

Daly, M., Wilson, M. Sex, Evolution, and Behavior, 2nd ed. North Scituate, MA: Duxbury, 1983.

Denham, W. Infant transport among the Ayyawara Tribe, Central Australia. Oceania 44: 253-277 (1974).

Draper, P. Social and economic constraints on child life among the !Kung. In The Kalahari Hunter Gatherers, R.B. Lee and I. Devore (Eds.). Cambridge, MA: Harvard University Press, 1977, pp. 200-217.

Eibl-Eibesfeldt, I. Ethology: The Biology of Behavior. New York: Holt, Rinehart, and Winston, 1975.

- Human ethology; concepts and implications for the sciences of man. The Behavioral and Brain Sciences 2: 1-57 (1979).

Ekman, P. Universals and cultural differences in facial expressions of emotion. In Nebraska Symposium on Motivation, J.K. Cole (Ed.). Lincoln, NE: University of Nebraska Press, 1971.

- Cross-cultural studies of facial expression. In Darwin and Facial Expressions, P. Ekman (Ed.). New York: Academic, 1973.

- Face muscles talk every language. Psychology Today 9:35-39 (1975).

- Frisen, R. Constants across cultures in face of emotion. Journal of Personality and Social Psychology 17: 124-129 (1971).

Emde, R.N., Kligman, D.H., Reich, J.H., Wade, T.D. Emotional expression in infancy: I. Initial studies of social signaling and an emergent model. In The Development of Affect, M. Lewis and L. Rosenblum (Eds.). New York: Plenum, 1978.

Erasmus, C. Work patterns in a Maya village. American Anthropologist 57: 322-333 (1955).

Feldman, S.S., Nash, S.C. Changes in responsiveness to babies during adolescence. Child Development S0: 942-949 (1979).

- - Interest in babies during young adulthood. Child Development 49: 617-622 (1978).

Field, T. Interaction patterns of term and preterm infants. In Infants Born at Risk, T. Field (Ed.). New York: SP Medical and Scientific Books, 1979, pp. 333-356.

Hall, E.T. The Silent Language. Greenwich, CT: Fawcett, 1959.

Hall, J.A. Gender effects in decoding nonverbal cues. Psychological Bulletin 85: 845-857 (1978).

Harpending, H. Regional variation in !Kung populations. In Kalahari Hunter-Gatherers, R. Lee and I. DeVore (Eds.). Cambridge, MA: Harvard University Press, 1976, pp. 152-165.

Hiatt, S.W., Campos, J.J., Emde, R.N. Facial patterning and infant emotional expression: Happiness, surprise and fear. Child Development 50: 1020 1035 (1979).

Hinde, R. The Biological Bases of Human Behavior. New York: McGraw-Hill, 1974.

Howell, N. The population of the Dobe area !Kung. In Kalahari Hunter-Gatherers, R. Lee and I. DeVore (Eds.). Cambridge, MA: Harvard University Press, 1976, pp. 137-151.

Ingram, G. If and when transformations are acquired by children. In Developmental Psycholinguistics: Theory and Application, D. Dato (Ed.). Washington, D.C.: Georgetown University Press, 1975.

Izard, C.E. The Face of Emotion. New York: Appleton Century-Crofts, 1971.

- Huebner, R.R., Risser, D., McGinnes, G.C. Dougherty, L.M. The young infant's ability to produce discrete emotional expressions. Development Psychology 16(2): 132-140 (1980).

Johnson, A. Time allocation in a Machiguenga community. Ethnology 14: 301-310 (1975).

Johnston, F., Kensinger, K. Fertility and mortality differentials and their implications for microevolutionary change among the Cashinahua. Human Biology 43: 356-364 (1971).

Kapłan, J.J., Larrick, J., Yost, J., Farrell, L., Greenberg, H., Hermann, K., Sulzer, A., Walls, K., Pederson, L. Infectious disease patterns in the Waorani, an isolated Amerindian population. American Journal of Tropical Medicine and Hygiene 29(2): 298-312 (1980).

Katz, M., Konner, M. The role of the father: An anthropological perspective. In The Role of the Father in Child Development, rev. ed., M. Lamb (Ed.). New York: Wiley, 1981.

Konner, M.J. Aspects of the developmental ethology of a foraging people. In Ethological Studies in Child Behaviour, N.G. Blurton Jones (Ed.). Cambridge: Cambridge University Press, 1972, pp. 285-304.

- Maternal care, infant behavior, and development among the !Kung. In The Kalahari HunterGatherers, R.B. Lee and I. DeVore (Eds.). Cambridge, MA: Harvard University Press, 1977, 219245.

Kurland, J., Gaulin, S. The evolution of male parental investment: Effects of genetic relatedness and feeding ecology on the allocation of reproductive effert. In Primate Males and Infants: An Evolutionary and Comparative Perspective, D. Taub (Ed.). New York: Van Nostrand Rheinhold, in press.

Lamb, M.E. The Role of the Father in Child Development, 2nd ed. New York: Wiley, 1981.

- Easterbrooks, M.A. Individual differences in parental sensitivity: Origins, components, and consequences. In Infant Social Cognition, M.E. Lamb and L.R. Sherrod (Eds.). Hillsdale, NJ: Erlbaum, 1981.

Lee, R. The !Kung San. Cambridge: Cambridge University Press, 1979. 
Lenneberg, E. The Biological Foundations of Language. New York: Wiley, 1967.

Lester, B., Zeskind, P. The organization and assessment of crying in the infant at risk. In Infants Born at Risk. T. Field (Ed.). New York: SP Medical and Scientific Books, 1979, pp. 121-144.

- A biobehavioral perspective on crying in early infancy. In Theory and Research in Behavioral Pediatrics, H. Fitzgerald. B. Lester and M. Yogman (Eds.). New York: Plenum, 1981, Vol. 1.

Lhermillier, A., Lhermiller, N. Vie Economique et Sociale d'une Unite Familiale Yanomami. Thesis, L'Ecole Pratique des Hautes Etudes. Paris (1974).

Maccoby, E.E., Jacklin, C.N. The Psychology of Sex Differences. Stanford, CA: Stanford University Press, 1974.

Mackey. W. Parameters of the adult male-child bond. Ethology and Sociobiology 1: 59-76 (1979).

Malatesta. C.Z. The expression and regulation of emotion: A lifespan perspective. In Emotion and Early Interaction, T. Field (Ed.). Hillsdale, NJ: Erlbaum. 1982, pp. 1-24.

Melancon, T. Marriage and reproduction among the Yanomamo Indians of Venezuela. Thesis, Department of Anthropology, Pennsylvania State University (1981).

Nag, M., White, B., Peet, R. An anthropological approach to the study of the economic value of children. Current Anthropology 19: 293-306 (1978).

Nash, S.C., Feldman, S.S. Sex role and sex-related attributions: Constancy and change across the family life cycle. In Advances in Developmental Psychology, M.E. Lamb and A. Brown (Eds.). Hillsdale, NJ: Erlbaum, 1981, Vol. 1.

- Sex role and sex-related attributions: Constancy and change across the family life cycle. In Advances in Developmental Psychology, M.E. Lamb and A. Brown (Eds.). Hillsdale, NJ: Erlbaum, 1981, Vol. 1.

Neel, J. Health and disease in unacculturated Amerindian populations. In CIBA Foundation Symposium No. 49 (N.S.) Symposium on Health and Disease in Tribal Societies. Amsterdam: Excerpta Medica, 1976.

Nerlove, S. Women's workload and infant feeding practices. Ethnology 13: 207-214 (1974).

Papousek, H., Papousek, M. Cognitive aspects of preverbal interaction between human infants and adults. In CIBA Foundation Symposium No. 33 (N.S.), Parent-Infant Interactions. Amsterdam: Excerpta Medica, 1975.

Pannabecker, B.J., Emde, R.N., Johnson, W., Stenberg, C., Davis, M. Maternal perceptions of infant emotions from birth to 18 months: A preliminary report. Paper presented to the biennial meetings of the International Conference on Infant Studies, New Haven, CT, 1980.

Parke, R.D. Fathers. Cambridge, MA: Harvard University Press, 1981.
Popkin, B. Time allocation of the mother and child nutrition. Ecology of Food and Nutrition 9: 1-14 (1980).

Redican, W. Adult male-infant interactions in nonhuman primates. In The Role of the Father in Child Development, M. Lamb (Ed.). New York: Wiley, 1976, pp. 345-385.

Rossi, A.S. A biosocial perspective on parenting. Daedalus 106: 1-30 (1977).

Steklis, H.D., Raleigh, M.J. Behavioral and neurobiological aspects of primate vocalization and facial expression. In Neurobiology of Social Communication in Primates, H.D. Steklis and M.J. Raleigh (Eds.). New York: Academic. 1979.

Stern. D. Mother and infant at play: the dyadic interaction involving facial, vocal, and gaze behaviors. In The Effect of the Infant on its Caregiver. $M$. Lewis and L. Rosenblum (Eds.). New York: Wiley. 1971, pp. 187-214.

- The First Relationship. Cambridge, MA: Harvard University Press, 1977.

Symons. D. The Evolution of Human Sexual Behavior. Oxford: Oxford University Press, 1979.

Szalai, A., Converse, P.E., Feldheim. P., Scheuch, E.K., Stone, P.J. The Use of Time: Daily Activities of Urban and Suburban Populations in Twelve Countries. The Hague: Mouton, 1972.

Tanner, N. On Becoming Human. Cambridge: Cambridge University Press, 1982.

Thompson, R.A. The father's case in child custody disputes: The contributions of psychological research. In Fatherhood and Family Policy, M.E. Lamb and A. Sagi (Eds.). Hillsdale, NJ: Erlbaum, 1983.

Tiger, L. Men in Groups. New York: Random House, 1969.

Trevarthen, C. Descriptive analysis of infant communicative behavior. In Studies in Mother-Infant Interaction, H. Schaffer (Ed.). New York: Academic, 1977, pp. 227-270.

- Descriptive analysis of infant communicative behavior. In Studies of Mother-Infant Interaction, H.R. Schaffer (Ed.). London: Academic, 1977.

Trivers, R. The evolution of reciprocal altruism. Quarterly Review of Biology 46(4): 35-57 (1971).

- Parental investment and sexual selection. In Sexual Selection and the Descent of Man, B. Campbell (Ed.). Chicago: Aldine, 1972, pp. 136179.

- Parental investment and sexual selection. In Sexual Selection and the Descent of Man, 18711971, B. Campbell (Ed.). Chicago: University of Chicago Press, 1972.

Van Hooff. J.A.R.A.M. The comparison of facial expressions in man and higher primates. In Methods of Inference from Animal to Human Behavior. M. Van Cranach (Ed.). Chicago: Aldine, 1976.

Weil, J. Comparative study of the organization of work: Productive time in three societies. Paper read 
at the annual meeting of the American Anthropological Association, Los Angeles, 1981.

Weisner, T., Gallimore, R. My brother's keeper: Child and sibling caretaking. Current Anthropology 18: 169-190 (1977).

Weiss, K. Demographic models for anthropology. Memoirs of the Society for American Archaeology, No. 27. American Antiquity 38(2) (1973).

Whiting, J., Whiting, B. Children of Six Cultures-A Psycho Cultural Analysis. Cambridge, MA: Harvard University Press, 1975.

Wiesenfeld, A.R., Malatesta, C.Z., DeLoach, L.L. Differential parental response to familiar and unfamiliar infant distress signals. Infant Behavior and Development 4: 281-295 (1981).

Wolff, $P$. The natural history of crying and other vocalizations in infancy. In Determinants of Infant Behavior. IV. B.M. Foss (Ed.). London: Methuen, 1969.

Ziajka, A. Prelinguistic Communication in Infancy. New York: Praeger, 1982.

Zuckerman, M., DeFrank, R.S., Hall, J.A., Rosenthal, R. Encoding and decoding of spontaneous facial expressions. Journal of Personality and Social Psychology 34: 966-978 (1976). 